Research Article

\title{
Study on the Physical Properties and Joint Evolution Characteristics of Three-Dimensional Reconstructed Coal
}

\author{
Yongning Wu, Zhe Zhang, Xinzhe Wang, Peiyang Zhu, Xin Yang, and Lishuai Jiang $\mathbb{C}$
}

State Key Laboratory of Mining Disaster Prevention and Control, Shandong University of Science and Technology, Qingdao 266590, China

Correspondence should be addressed to Lishuai Jiang; lsjiang@sdust.edu.cn

Received 16 November 2021; Accepted 9 December 2021; Published 28 December 2021

Academic Editor: Zhengyang Song

Copyright $(92021$ Yongning Wu et al. This is an open access article distributed under the Creative Commons Attribution License, which permits unrestricted use, distribution, and reproduction in any medium, provided the original work is properly cited.

There are various complex joints (fissures), laminae, and other soft structural surfaces in the roadway enclosure, and the existence of these soft structural surfaces seriously affects the stability of the roadway enclosure. In order to study the mechanical properties of the coal body and the development of joints during coal fracture, this paper establishes a three-dimensional model of the fracture structure of the coal body based on CT scanning and three-dimensional reconstruction technology. On this basis, a 3D numerical model of the equivalent nodal coal body is constructed, uniaxial compression simulation analysis is performed, and the joint evolution development law of the coal sample is studied by the built-in joint monitoring program of PFC3D. The results show that the larger the effective joint area and larger the joint size inside the coal sample, the smaller the compressive strength of the coal sample. The increase of joint size and joint surface area increased the ductility and stress-strain curve multipeak phenomenon of the coal sample to some extent. During the rupture of the coal sample, the changes of each phase of the statistical curve of joint number and the phases of the stress-strain curve of the coal sample are compatible.

\section{Introduction}

Coal body is a kind of heterogeneous geological body with complex composition and containing many kinds of fissures (joints), in which the complex occurrence, trace length, and density of joints are the main factors that determine the mechanical properties and deformation law of coal and rock mass. Joints are classified as through joints, semithrough joints, and nonthrough joints according to the degree of through, and due to the invisibility of nonthrough joints, the information of joint occurrence and trace length cannot be directly obtained. Therefore, nonthrough joints become one of the most difficult to study. And the existence of these joints is very likely to lead to stress concentration or expansion of the weak structural surface in the roadway enclosure. Therefore, the study of the influence of the joint structure on the mechanical properties of the coal body can better understand the failure process of the coal body, which is conducive to further revealing the causes of the instability of the surrounding rock and provides a research basis for the stability evaluation of mining projects and related work. Many scholars have carried out a large number of experimental studies on the influence of joint structure on the mechanical properties of rock mass. Liu et al. studied the influence of angle and roughness of nonthrough joints on the failure mode of rock mass by PFC2D [1] and found that the rock mass was mainly tensile failure when the angle of joints was small or the roughness was low, and the rock mass was mainly tensile shear failure when the angle of joints was large or the roughness was high; Fereshtenejad et al. studied the mechanical properties and the evolution of internal fine cracks of rock mass with anchored through joints by indoor experiments and numerical simulations [2-4]. The experiments showed that the greater the normal stress, the higher the shear strength of anchored jointed rock mass; Liu et al. studied the influence of the angle of the through joints on the failure strength and failure mode of the specimens through Brazilian splitting tests and explored the damage mechanism and joints expansion law of the specimens [5-8]. At present, most studies on joints focus more on the influence of the 
characteristic parameters of through joints on the mechanical properties and failure mode of rock masses, and not enough attention has been paid to the study of the damage mechanism of nonthrough joints. Bing et al. carried out direct shear tests on nonthrough jointed rock masses and studied the strength and deformation characteristics of nonthrough jointed rock masses with different joint undulation angles and the mesoexpansion mechanism of nonpenetrating jointed rock masses [9]; Yang et al. prepared samples of noncoplanar and nonthrough jointed rock mass by using rocklike materials, studied the transfer law of the force chain of noncoplanar and nonthrough jointed rock mass, and analyzed the mechanism of shear mechanical behavior from the mesoscopic point of view [10]; Yang et al. prepared intact rock specimens, rock specimens with single joints, and rock specimens with double joints, and carried out uniaxial compression tests on each type of specimens to study the influence of embedded nonthrough joints on the mechanical properties of rock masses [10-16]. The above studies mainly focus on the mechanical properties and damage mechanism of rock masses containing prefabricated, controllable, and small amount of nonthrough joints, which are limited by the interference of human influences, and most of the studies focus on the observation surface of rock masses for certain analysis. With the development of technology, some scholars obtained microfine information such as joint rate, joint occurrence, and internal images of coal rock bodies through CT scan and studied the influence of fine structure within coal rock bodies on their mechanical properties by combining with numerical analysis methods. Song et al. combined the electron microscopy scanning technique and RFPA3D to conduct a fine view test of joint extension in barite containing a single pore, and the results showed that nonhomogeneity has a large influence on the joint extension characteristics in rock samples [17-19]; Asadizadeh et al. studied the influence of the original joint structure on the macroscopic joint characteristics of coal and rock based on CT scanning technology and obtained the different three-dimensional fractal dimensions of the internal damage fracture surface of coal and rock specimens under different confining pressures [20]; Song et al. studied the influence of different joint parameters on the rock strength by 3DEC numerical simulation software and analyzed the sensitivity of the rock strength to each parameter [21]. In summary, in the current research process, the study of the mechanical properties and damage modes of joints on coal rock body mainly adopts physical methods and numerical simulation to establish the model of coal body containing small amount of, prefabricated, and through joints, and studies the damage mechanism of coal body by conducting uniaxial or triaxial compression test. Although the above methods can simulate the nonhomogeneity of body, the constructed nodular coal body model does not have much research on the morphology and distribution characteristics of the irregular structure of joints in coal body. Therefore, this paper mainly obtains the internal joints microstructure of coal body based on CT scanning technology, uses mathematical methods to process and analyze the extracted internal joints, and combines Avizo software and PFC3D to realize 3D reconstruction of coal body joints. The influence of coal body joints on the mechanical behavior of coal body such as compressive strength and deformation law is studied in depth, which provides a method to further understand the influence of coal rock joints structure on its mechanism.

\section{Spatial Distribution Pattern of Coal Body Joints}

2.1. Specimen Preparation and CT Scan Experiments. The coal samples used in the experiment are taken from the test taken from Hongqinghe coal mine, the sampling at 103 working face. The bulk coal body with large volume is selected for sampling, and cylindrical specimens with 100-mm height and $50 \mathrm{~mm}$ diameter and $50 \mathrm{~mm}$ height and $50 \mathrm{~mm}$ diameter are obtained by drilling and grinding, as shown in Figure 1.

In order to obtain the complex joint structure and related information within the coal, the CT detection technique is used to obtain the internal structure information of coal containing joints, organic matter, and minerals (impurities) without damaging the original structure inside the coal body. The X-ray 3D microscope nanoVoxel-4000 system of Tianjin Sanying Technology Company is used for the scanning test (Figure 2). The main parameters of the scan are voltage $150 \mathrm{kV}$, current $150 \mu \mathrm{A}$, exposure time $0.8 \mathrm{~s}$, magnification 4.6 , spatial separation rate $0.127 \mathrm{~mm}$, and frame number $1400 / 360^{\circ}$. A total of 201 16-bit grayscale images of $850 \times 850$ pixels are obtained by CT scanning of the entire standard coal sample.

2.2. Fine-Scale 3D Structure of Coal Fractures. The digital image obtained after CT scan processing is a high-density image, and the specimen structure is divided according to the density level, in which white is the high-density area, representing the minerals in the coal, black is the low-density area, representing the fissures in the coal rock, and gray is the coal matrix. At the same time, in order to minimize the error and improve the accuracy and efficiency of processing the internal nodules of the coal rock body, the standard $100 \mathrm{~mm} \times 50 \mathrm{~mm}$ image of the CT scan is divided into two $50 \mathrm{~mm} \times 50 \mathrm{~mm}$ cylindrical specimens, which are processed and extracted and rendered separately by Avizo image processing software to establish a three-dimensional data set of the coal body and obtain the overall layout of the fracture and mineral structure inside the coal rock body, so as to understand the internal information of the specimens more intuitively and comprehensively [23, 24]. As shown in Figure 3, the coal rock specimen, the $3 \mathrm{D}$ rendering of the scanned specimen, and the internal fracture mineral map of the specimen are shown, respectively. The internal fracture mineral map of the specimen for further study obtains its specific fracture information and fracture spatial distribution characteristics.

The internal joints of the digital image of the coal body processed by Avizo software are extracted and marked according to the area of individual joints. As shown in 

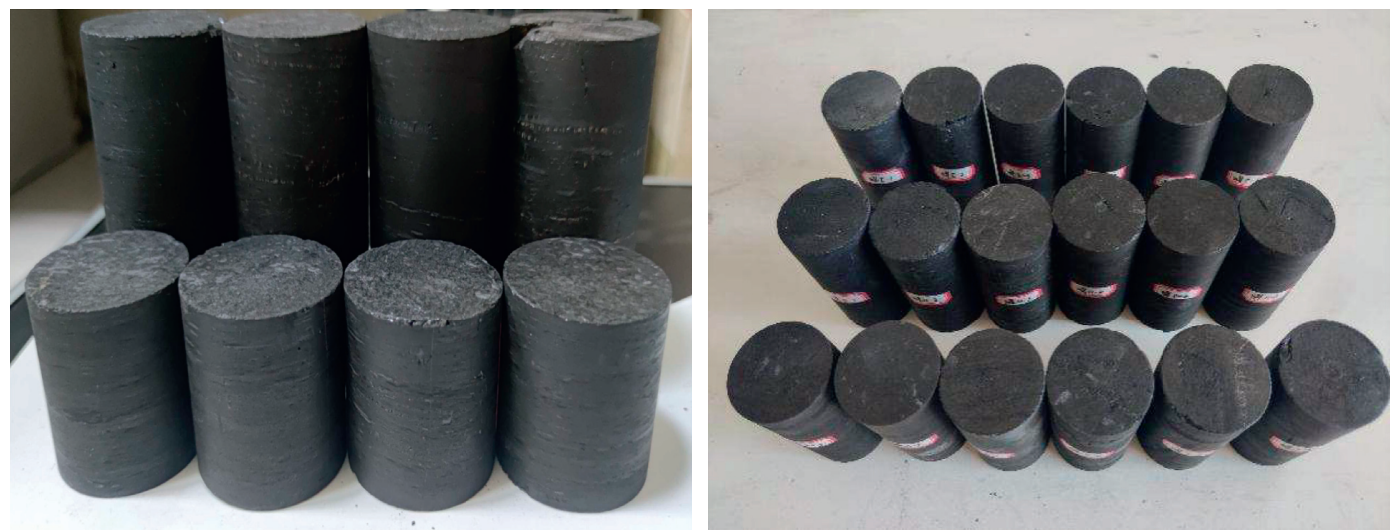

Figure 1: Coal sample specimen.
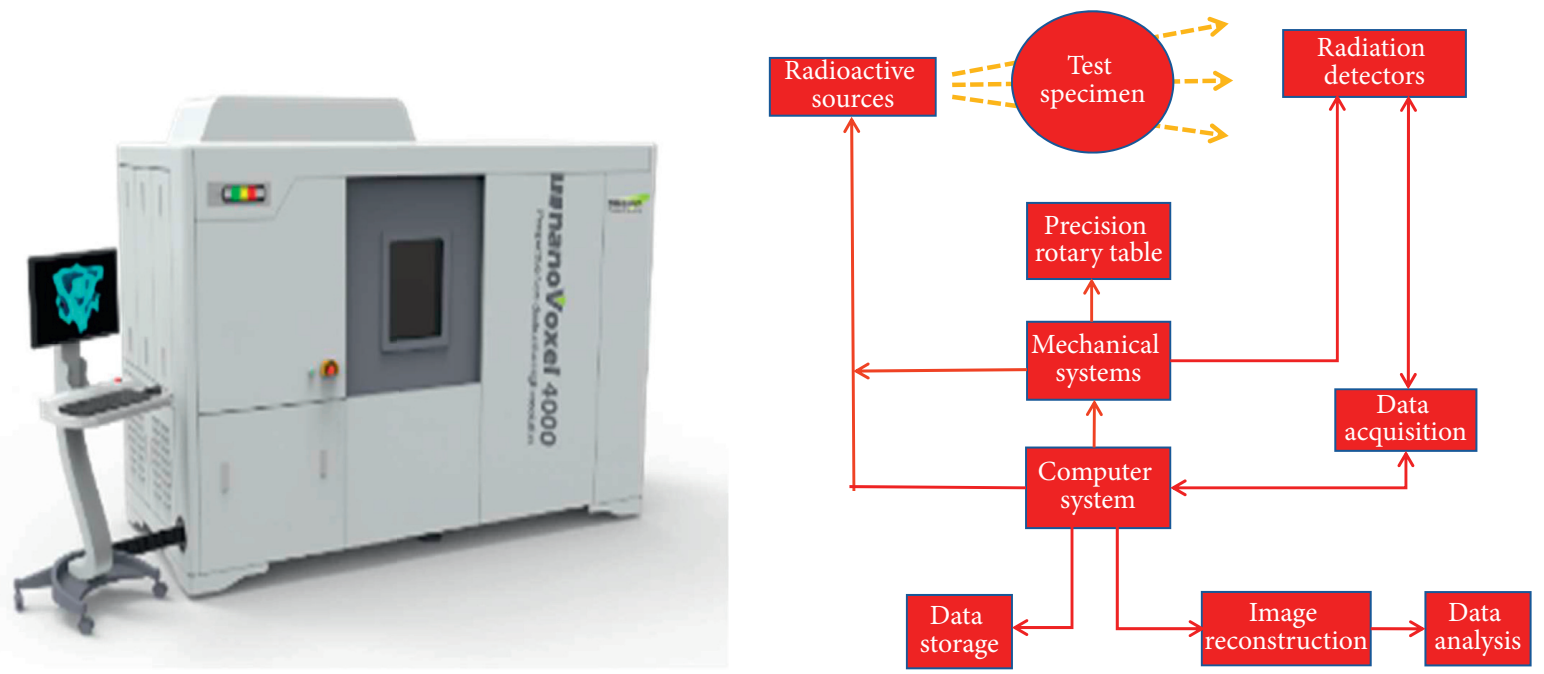

FIgURE 2: High-resolution CT scan test system [22].

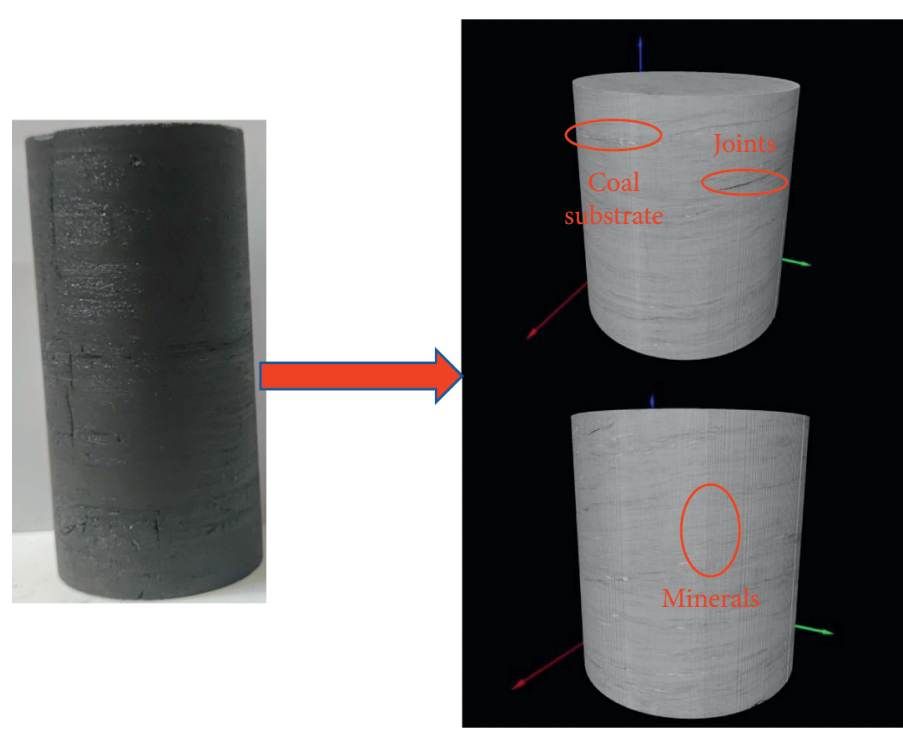

Coal rock specimens

$3 \mathrm{D}$ rendering of the scanned specimen

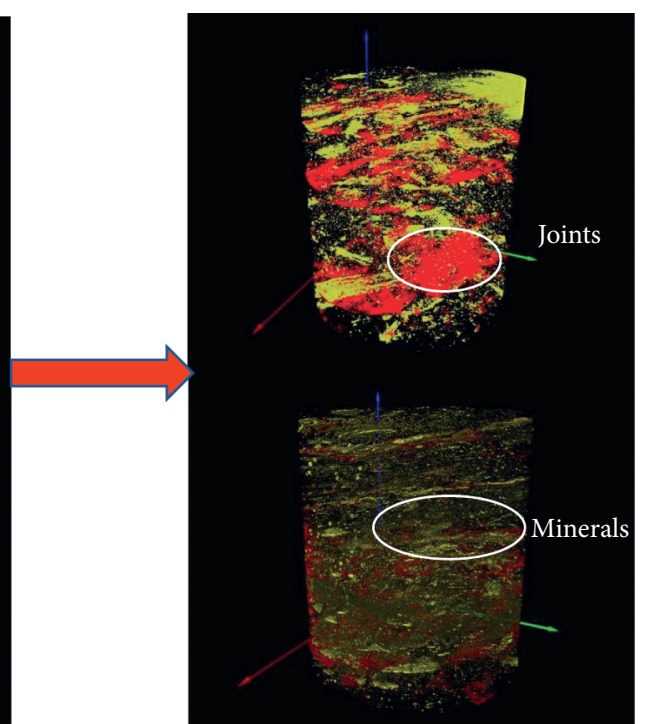

Figure 3: CT scan results of coal samples. 
Figure 4, the joint structures of the upper and lower parts of coal samples 1, 2, 3, 4, and 5 are shown, respectively. According to the images, it can be clearly seen that the coal body contains a large number of joint structures internally, as well as the intricate position relationship between the joints.

From the joint structure and distribution inside the coal body after CT scan, it can be seen that the size of the joints varies, basically nonthrough joints, and the degree of joint development varies from one coal sample to another. From the upper (a) and lower (b) parts of coal sample 1, it can be seen that the distribution of joints is denser at the two ends of the sample and sparser in the middle, and the size of joints gradually becomes larger from the top to the bottom, with clear hierarchy, mostly parallel joints. From the end of coal sample 2, the joints are gathered in the upper part of the sample and contain a semithrough fracture zone, while the lower part of joints is small and scattered joints. The distribution of joints in coal sample 3 is more scattered and uniform, only a small number of joints of larger size exist in the upper and lower ends, and the middle coal sample 4 has little difference in size between the overall joints, but the joints are more complex and interlocked, and there are joints perpendicular to each other at about $90^{\circ}$ in the middle of the sample. The coal sample 5 has joints concentrated in the lower part of the middle of the sample, the size difference between the joints is very different, and the angle is a variable.

In order to improve the efficiency and analyze the morphological characteristics of the internal joints in coal samples more accurately and specifically, the joints are sorted according to their area, the weak joints with an area of less than $1 \mathrm{~mm}^{2}$ are excluded, and more representative joints are selected for statistical analysis $[25,26]$.

From the statistical results, it can be seen that the angles and sizes of joints within different coal samples vary greatly in distribution, further demonstrating the characteristics of nonuniform distribution of joints in coal samples. In order to analyze the geometric characteristics of the joints in depth, the number of joints falling within each interval range is counted sequentially at $1 \mathrm{~mm}$ and $5^{\circ}$ intervals according to the length and angle size of the joints, and the percentage of the number of joints within each interval to the total number of effective joints is calculated. As shown in Figure 5, the maximum angle of joints in coal sample 1 is $84.27^{\circ}$ and the maximum length of joints is $31 \mathrm{~mm}$, while the highest number of joint angles and sizes fell in the range of $5^{\circ}-10^{\circ}$ and $1-2 \mathrm{~mm}$, accounting for $43.51 \%$ and $30.08 \%$ of the effective joints, respectively. The maximum angle of joints in coal sample 5 is $84^{\circ}$, and the maximum size is $64 \mathrm{~mm}$. The highest frequency of joint angle and size were also distributed in the range of $5^{\circ}-10^{\circ}$ and $1-2 \mathrm{~mm}$, accounting for $26.79 \%$ and $54.37 \%$ of the effective joint proportion, respectively. Combining the individual statistical graphs in Figure 5, it can be concluded that the highest frequency joint angles and sizes of the five coal samples are the same, and all of them are $5^{\circ}-10^{\circ}$ and $1-2 \mathrm{~mm}$; thus, it can be seen that the joint angles and sizes that account for the major proportion within the coal samples extracted from the same coal seam are consistent; however, the maximum sizes and maximum nodal angles within different coal samples are different and differ greatly from each other. The main factor leading to the variation of strength between coal samples is then caused by the larger size and angle nodules. Through comparison, it can be found that the number of joints in different coal samples is very different, so the influence of the number of joints on the strength of coal samples is also a key factor to be studied. The distribution pattern of CT scan images of fractures in different coal samples in Figure 4 and the statistical results of joint characteristic parameters in Figure 5 show that the characteristics of joints in different coal samples differ significantly from each other, mainly in several aspects, such as joint angle, joint size, joint distribution mode, and joint quantity. Therefore, further research on the specific influence of nodal characteristic parameters on the mechanical properties of coal samples is needed. At the same time, it can be predicted that the internal fracture network of the Hongqinghe mine coal sample is obviously developed, intersected, and complicated, and in addition to the more obvious main fractures, it is accompanied by many small fractures, which intersect with the main fractures and form an intricate netlike fracture structure in space.

\section{Three-Dimensional Reconstruction of Coal Body Fractures Based on Numerical Model of Nonthrough Joints}

In order to further study the influence of joint structure on the mechanical properties and deformation pattern of coal samples, the joint characteristic parameters and internal joint structure obtained based on CT scanning digital image processing technology are processed by combining mathematical methods, and the three-dimensional coal sample model considering the fracture structure of coal samples is established by using PFC3D discrete element software. At the same time, in order to quantitatively analyze the geometric characteristics of the joint structure inside the coal sample and the spatial distribution characteristics in the coal sample, the main characteristic parameters such as the length of the joints, the area of the joints, and the angle are extracted using the label analysis module in Avizo software to do specific analysis.

A large number of statistics show that the geometric characteristic parameters of the joints obey a certain distribution law. In this paper, based on the joint structure existing inside the natural coal sample, the effective joints (joints with area less than or equal to $1 \mathrm{~mm}^{2}$ ) are divided into ten groups according to the ranking of joints area, and less than $1 \mathrm{~mm}^{2}$ as the 11 th group, and the geometric characteristic parameters of joints within each group are weighted based on this basic basis to obtain the weighted joints angle and size (Table 1). The calculation process is as follows:

$$
\bar{\alpha}=\frac{\sum_{i=1}^{n} \alpha_{i} * S_{i}}{\sum_{i=1}^{n} S_{i}},
$$

where $\bar{\alpha}$ is the weighted average angle, $\alpha_{i}$ is the angle of the $i$ th joint, and $S_{i}$ is the area of the $i$ th joint. 


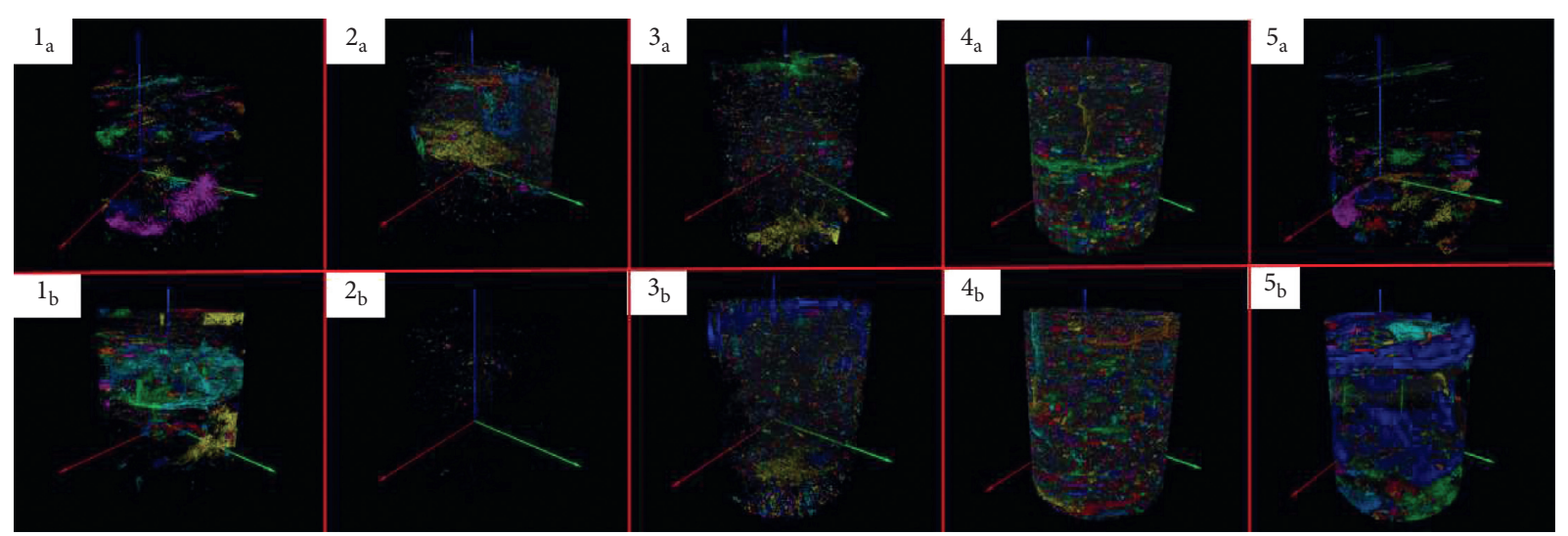

FIgURE 4: Internal fracture structure of the coal sample.

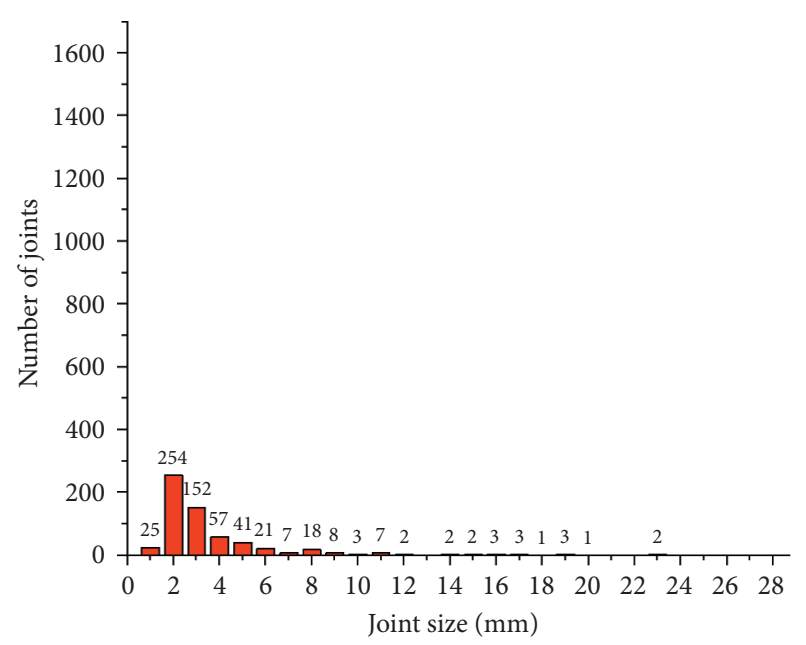

(a)

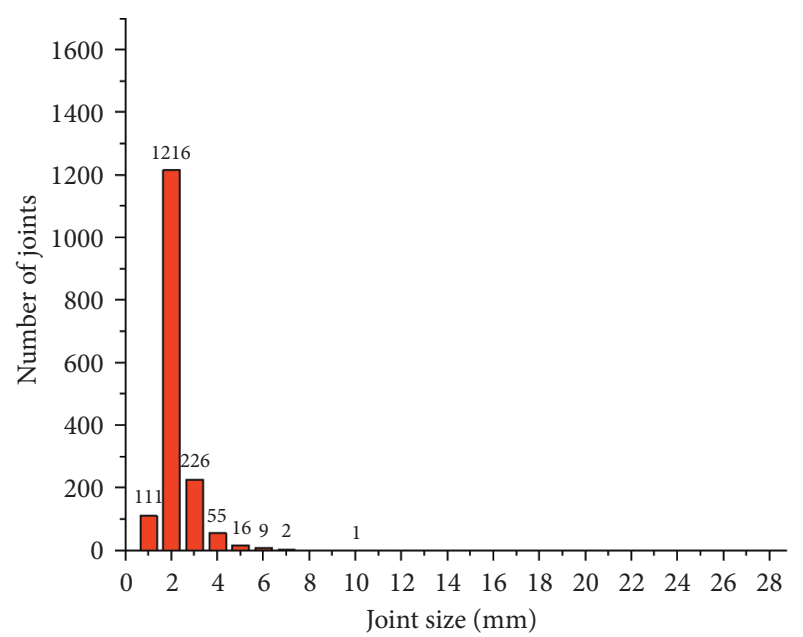

(c)

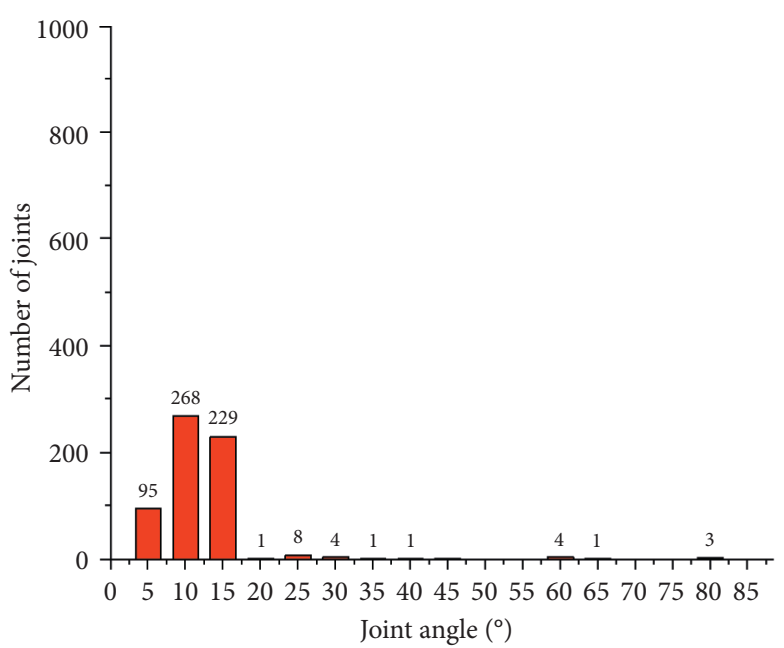

(b)

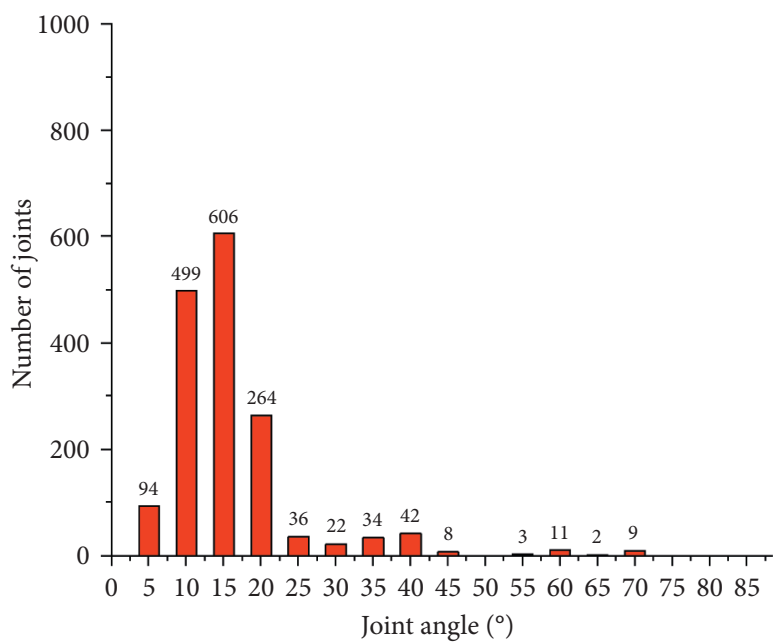

(d)

FIGURE 5: Continued. 


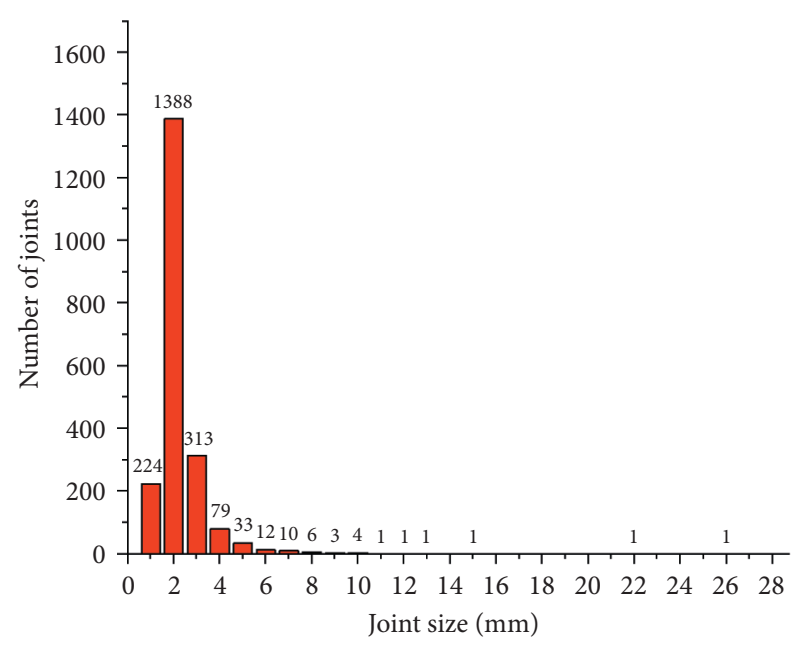

(e)

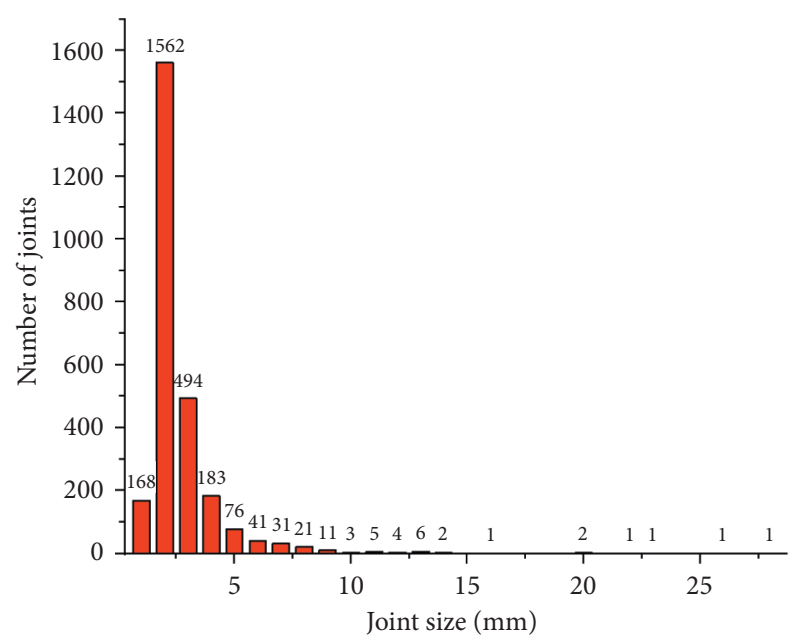

(g)

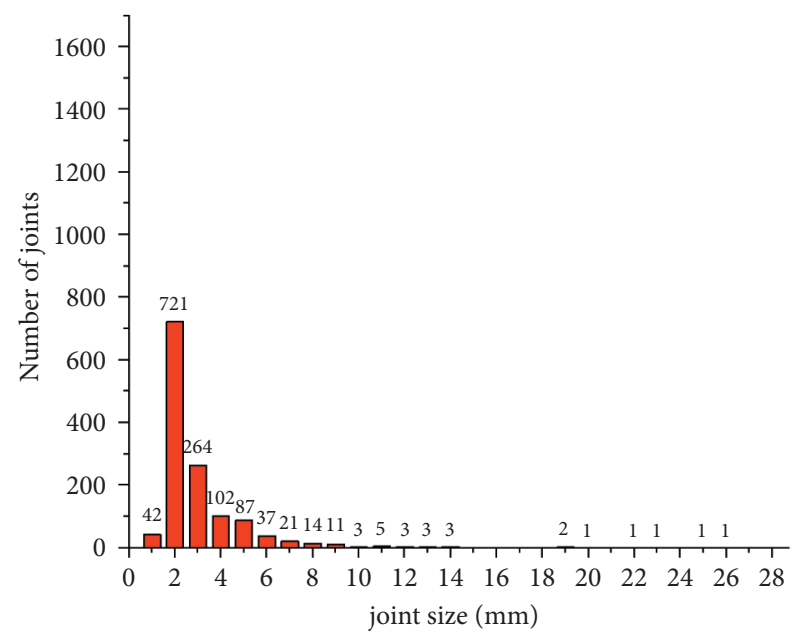

(i)

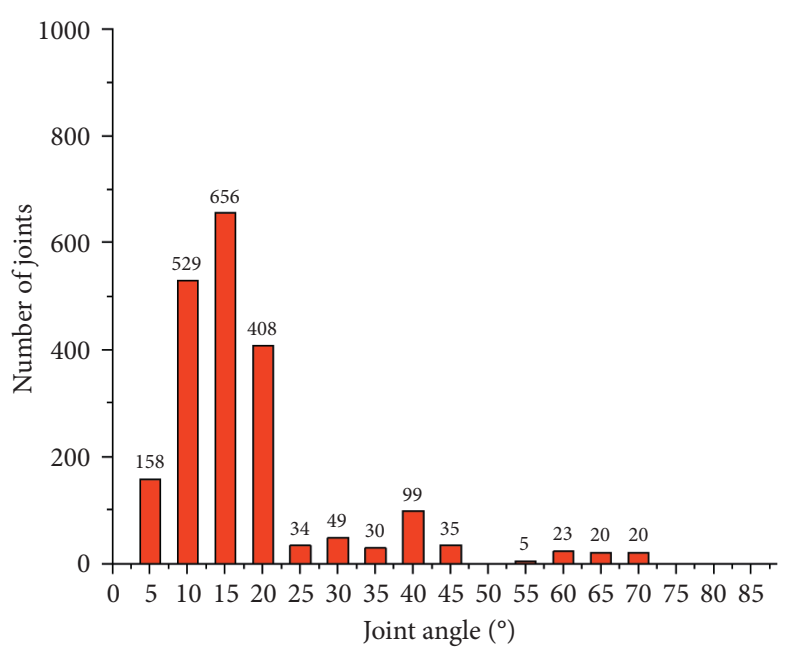

(f)

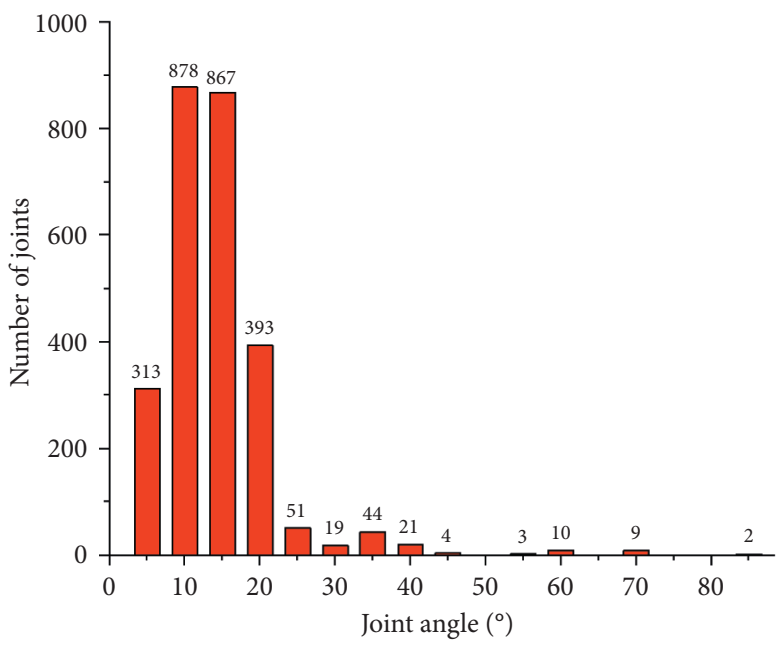

(h)

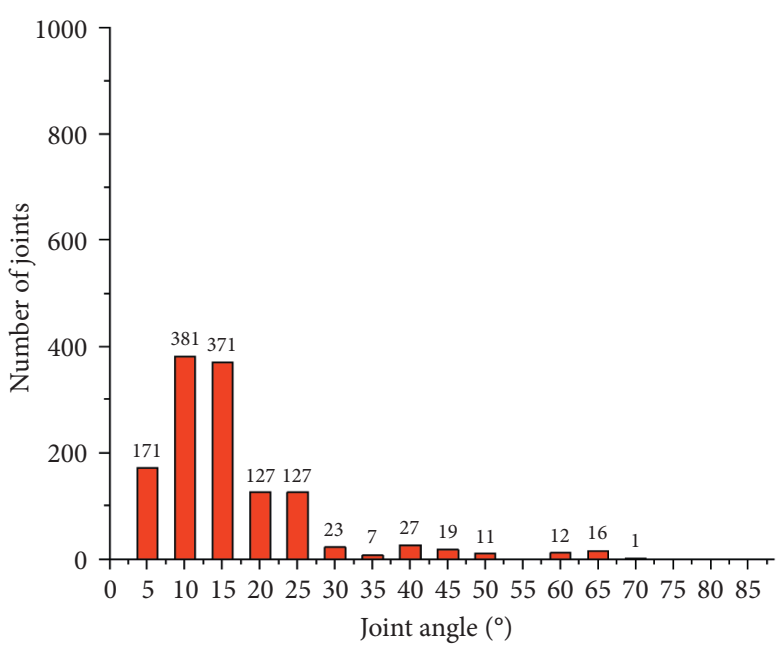

(j)

FigURE 5: Statistics of nodal feature parameters. (a) Effective joint length statistics of coal sample 1. (b) Effective joint angle statistics of coal sample 1. (c) Effective joint length statistics of coal sample 2. (d) Effective joint angle statistics of coal sample 2. (e) Effective joint length statistics of coal sample 3. (f) Effective joint angle statistics of coal sample 3. (g) Effective joint length statistics of coal sample 4. (h) Effective joint angle statistics of coal sample 4. (i) Effective joint length statistics of coal sample 5. (j) Effective joint angle statistics of coal sample 5. 
TABLe 1: Parameters of geometric characteristics of coal sample 4 joints.

\begin{tabular}{lccc}
\hline Joint group number & Joint diameter $(\mathrm{cm})$ & Joint surface density $\left(\mathrm{cm}^{2} / \mathrm{cm}^{3}\right)$ & Joint angle $\left({ }^{\circ}\right)$ \\
\hline 1 & 1.816 & 0.097 & 9.821 \\
2 & 0.452 & 0.012 & 10.018 \\
3 & 0.312 & 0.006 & 10.467 \\
4 & 0.250 & 0.004 & 10.821 \\
5 & 0.209 & 0.003 & 10.900 \\
6 & 0.174 & 0.002 & 11.019 \\
7 & 0.160 & 0.002 & 11.513 \\
8 & 0.147 & 0.001 & 11.614 \\
9 & 0.135 & 0.001 & 12.425 \\
10 & 0.125 & 0.001 & 12.502 \\
11 & 0.007 & 0.059 & 44.440 \\
\hline
\end{tabular}

$$
\bar{\beta}=\frac{\sum_{i=1}^{n} \beta_{i} * S_{i}}{\sum_{i=1}^{n} S_{i}}
$$

where $\bar{\beta}$ is the weighted average diameter, $\beta_{i}$ is the diameter of the $i$ th joint, and $S_{i}$ is the area of the $i$ th joint.

$$
\rho=\frac{\sum_{i=1}^{n} S_{i}}{V},
$$

where $\rho$ is the nodal surface density, $S_{i}$ is the area of the ith joint, and $V$ is the volume of the joints.

The joint geometry characterization parameters of coal samples are obtained by using equations (1)-(3). Taking coal sample 4 as an example, the results of Table 2 are obtained by calculation, and the nonuniform distribution DFN mesh (as is shown in Figure 6) model is established based on the DFN module in PFC3D, which can more accurately characterize the nonhomogeneous characteristics of coal rocks.

In order to better reconstruct the three-dimensional coal samples in the PFC3D model, a flat joint model is used in this numerical simulation, while the trial-and-error method is used to calibrate the microscopic parameters of the model based on the literature review and previous experience, and the microscopic parameters of the numerical model are continuously adjusted to match the indoor experiments by combining with the control variable method. The fine-scale parameters of the model mainly include the particle microscale parameters and the contact model fine-scale parameters, and Table 3 shows the specific parameters after calibration.

Based on the completion of the joint structure reconstruction and the selection of the base parameter calibration, the specific process of $3 \mathrm{D}$ modeling in this paper is as follows.

A cylindrical standard coal sample with dimensions of $100 \mathrm{~mm}$ in height and $50 \mathrm{~mm}$ in diameter is created in PDC3D, the minimum particle radius is set to $0.26 \mathrm{~mm}$, the minimum particle size ratio is set to 1.5 , and the random seed is set to 10001, generating a total of 14698 particles and 39549 contacts; the initial model is shown in Figure 7.

(1) The DFN fracture structure obtained from the 3D reconstruction is imported into the standard coal sample numerical model in turn, and the PFC3D model of the reconstructed coal sample was obtained as in Figure 8.

(2) In order to verify the reliability of the model, the reconstructed PFC3D model of the coal sample is subjected to uniaxial compression test, and in order to increase the stability of the numerical calculation, the loading rate is set to $0.001 \mathrm{~cm} /$ per cycle step. Uniaxial loading is performed to obtain the stressstrain curve of coal sample 4 . The stress-strain curve obtained from the numerical experiment is compared with that obtained from the physical experiment, and it is found that the two are in great agreement. As shown in Figure 9, $\sigma_{c}=8.66 \mathrm{MPa}$ obtained from the numerical simulation, which is only $0.11 \mathrm{MPa}$ different from that obtained from the experiment.

\section{Study on Mechanical Properties and Microfracture Evolution of Coal Mass}

In order to further study the mechanical properties of coal samples and the expansion law of nonthrough joints in their damage process, this paper conducts uniaxial compression tests and related numerical simulation studies on standard coal samples obtained in the field. The five coal samples after the CT scan are calculated and numbered in order according to their internal joint areas from smallest to largest: 1, 2, 3, 4, and 5. The uniaxial compression experiments are carried out on a WAW31000 microcomputer-controlled electrohydraulic servo testing machine at Shandong University of Science and Technology, as shown in Figure 10.

4.1. Effect of Internal Joint Characteristics of Coal Samples on Their Mechanical Properties. According to the experimental results, the uniaxial compressive strengths of different specimens are obtained as shown in Figure 11, and it can be seen that the overall compressive strength of coal samples shows a monotonically decreasing trend with the increase of the joint area. Coal sample 2 and coal sample 4 do not have a decrease in compressive strength compared with the previous coal sample due to the increase of the joint area. Combining the main characteristic parameters of the 
TABle 2: Microscopic parameters of the coal sample model.

\begin{tabular}{|c|c|c|c|c|c|}
\hline \multicolumn{2}{|c|}{ Particle microscopic parameters } & \multicolumn{2}{|c|}{$\begin{array}{c}\text { Flat joint contact model } \\
\text { microparameters }\end{array}$} & \multicolumn{2}{|c|}{ Arithmetic parameter } \\
\hline$\rho s\left(\mathrm{~kg} / \mathrm{m}^{3}\right)$ & 2700 & $N$ & 4 & $K n(\mathrm{GPa})$ & 1.09 \\
\hline $\mathrm{R} \min (\mathrm{mm})$ & 0.10 & $\mu$ & 0.55 & $K s(\mathrm{GPa})$ & 1.09 \\
\hline $\mathrm{R} \max / \mathrm{R} \min$ & 1.5 & $\sigma t(\mathrm{MPa})$ & 0.55 & $\operatorname{coh}(\mathrm{MPa})$ & 4 \\
\hline$E p(\mathrm{GPa})$ & 1.0 & $c(\mathrm{MPa})$ & 4 & $\varphi\left({ }^{\circ}\right)$ & 20.8 \\
\hline$p$ & 1.3 & $\varphi\left({ }^{\circ}\right)$ & 20.8 & $\sigma t(\mathrm{MPa})$ & 4 \\
\hline$p$ & 0.5 & $E(\mathrm{GPa})$ & 1 & & \\
\hline & & $K$ & 1 & & \\
\hline
\end{tabular}

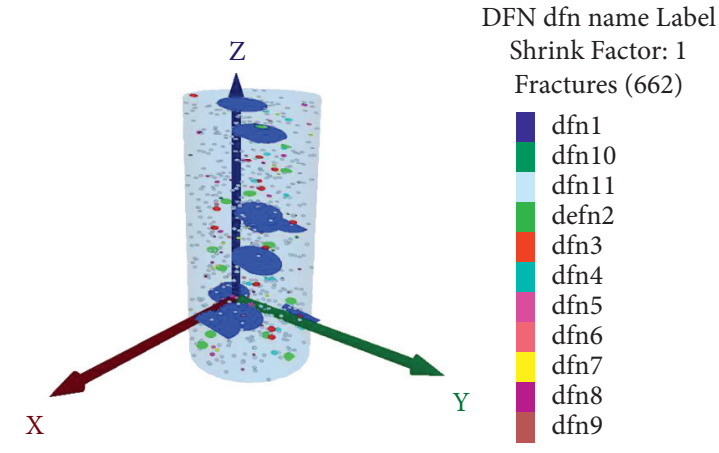

Figure 6: Coal sample 4 fracture structure.

TABLE 3: Main characteristic parameters of the internal joints of the coal samples.

\begin{tabular}{|c|c|c|c|c|c|c|}
\hline $\begin{array}{l}\text { Name of coal } \\
\text { sample }\end{array}$ & $\begin{array}{c}\text { Joint area } \\
\left(\mathrm{cm}^{2}\right)\end{array}$ & $\begin{array}{l}\text { Joint surface density } \\
\left(\mathrm{cm}^{2} / \mathrm{cm}^{3}\right)\end{array}$ & $\begin{array}{c}\text { Effective joint area } \\
\left(\mathrm{cm}^{2}\right)\end{array}$ & $\begin{array}{c}\text { Percentage of effective } \\
\text { throttling }\end{array}$ & $\begin{array}{l}\text { Size range } \\
(\mathrm{cm})\end{array}$ & $\begin{array}{c}\text { Angle range } \\
\left({ }^{\circ}\right)\end{array}$ \\
\hline 1 & 146.85 & 0.75 & 100.75 & 68.61 & $0.08-3.140$ & $4.63-84.27$ \\
\hline 2 & 202.98 & 1.03 & 99.77 & 49.15 & $0.068-4.00$ & $4.63-84.27$ \\
\hline 3 & 235.4 & 1.20 & 193.3 & 84.30 & $0.06-4.900$ & $4.63-84.27$ \\
\hline 4 & 420.4 & 2.14 & 210.72 & 50.12 & $0.075-2.72$ & $4.63-84.27$ \\
\hline 5 & 618.39 & 3.15 & 418.38 & 77.84 & $0.077-6.40$ & $4.63-84.27$ \\
\hline
\end{tabular}

internal joints of coal samples in Table 3, for further analysis, by comparing the data of coal sample 1 and coal sample 2 in the table, the total area of joints is larger in coal sample 2 than in coal sample 1, the effective joints area (effective joints: area greater than or equal to $1 \mathrm{~mm}^{2}$ ) is larger in coal sample 1 than in coal sample 2, and the size range is not much different; relatively speaking, the main control factor that causes the compressive strength of coal sample 2 to be larger than that of coal sample 1 is the effective joints area. The effective joint area of coal sample 3 and coal sample 4 is similar, and the difference is only $17.42 \mathrm{~cm}^{2}$, while the difference between their maximum sizes reaches $2.18 \mathrm{~cm}$, so the main control factor that causes the compressive strength of coal sample 4 to be larger than that of coal sample 3 is the size range, especially the influence of the maximum joint size. The effective joint area of coal sample 5 is the largest among the five coal samples, $418 \mathrm{~cm}^{2}$, the joint size range is from $0.077 \mathrm{~cm}$ to $6.40 \mathrm{~cm}$, and the uniaxial compressive strength of coal sample 5 is the lowest, $6.56 \mathrm{MPa}$. Because the five coal samples are collected from the same coal seam, the size range of the internal joints of coal samples is basically the same, at $4.63-84.27^{\circ}$.

The stress-strain curves of the five coal samples are obtained by processing the experimental data, as shown in Figure 12, which are similar to the stress-strain curves of uniaxial compression of rocks, with five stages: compressiondensity, elasticity, crack expansion, damage, and postpeak. And combined with Table 3 and Figure 11, it can be seen that with the increase of the joint area, the elastic-plastic characteristics of the coal samples become more and more obvious, and the stress-strain curves show different degrees of undulation and multiple peaks near the peak strength of the coal samples. Especially in coal sample 3 and coal sample 5, due to the large size of the internal joints, make the formation of more independent small blocks in the interior, and the destruction of small blocks occurs several times before and after the coal sample reaches the peak strength, which enhances the ductility and strength of the coal sample.

Through the above analysis, when the effective area of internal joints of coal samples is similar, the size of joints is 


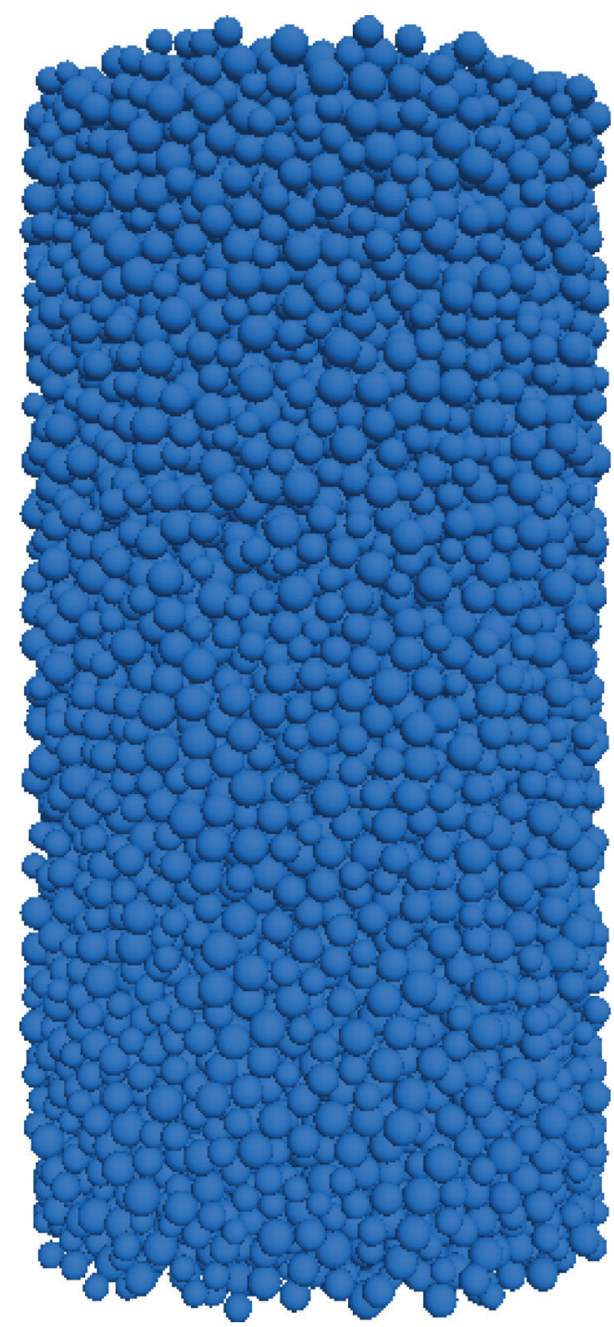

Figure 7: Initial model of coal sample PFC3D.

the main controlling factor. When the size of internal joints of coal samples is similar, the effective area of joints is the main controlling factor, from which it can be concluded that the larger the effective area of internal joints of coal samples and the larger the size of joints, the smaller the compressive strength of coal samples. At the same time, the increase of the size and area of joints increases the ductility and multipeak phenomenon of coal samples to some extent.

\subsection{Characterization of the Joint Evolution during the Rupture} of a Three-Dimensional Reconstructed Coal Sample. The internal joints of the fractured coal sample mainly consist of primary and secondary joints. In order to further study the joint extension evolution process of the coal sample, this paper presents a specific analysis of the joint generation and development process of the internal joints of the coal sample on the basis of the $3 \mathrm{D}$ reconstructed coal sample. The constructed $3 \mathrm{D}$ reconstructed model is subjected to uniaxial compression, the joints are extracted separately by using the built-in program of PFC3D to record the whole process of secondary joints generation, the key joints are extracted for analysis by combining with the stress-strain curve, and the

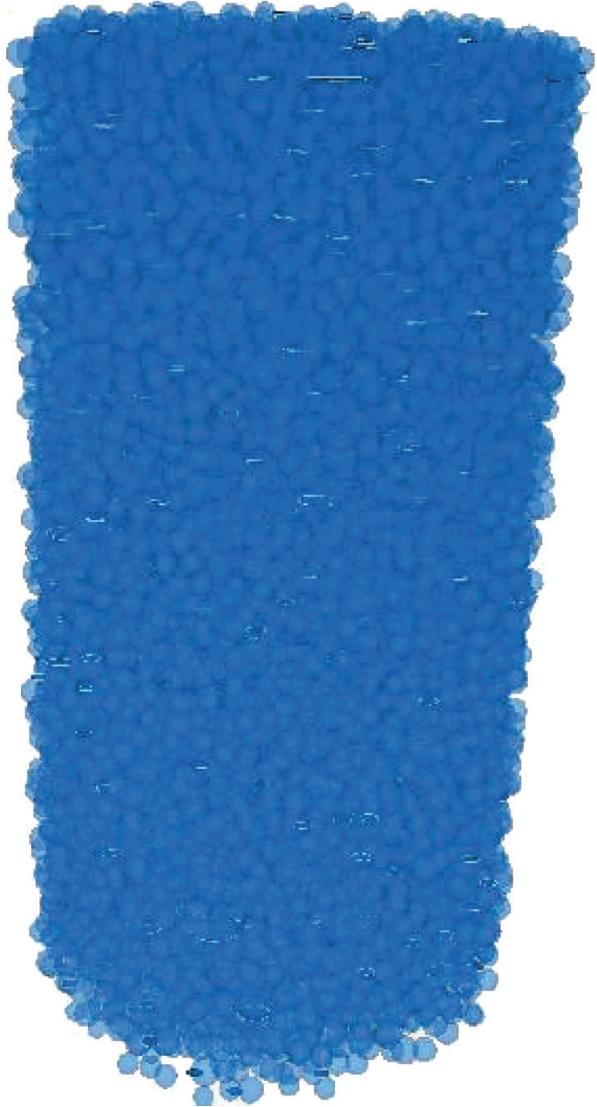

FIGURE 8: Reconstructed PFC3D model of coal sample.

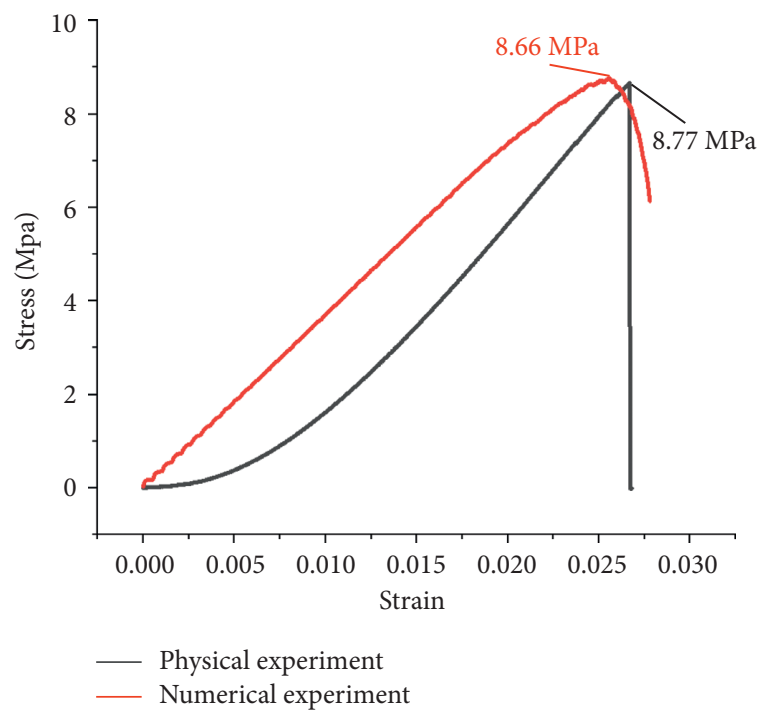

FIgURE 9: Comparison of numerical simulation and experimental stress-strain curves for coal samples under uniaxial compression.

number of joints is statistically studied as the joints characteristics to quantitatively characterize the extensional evolution of coal sample rupture process, as shown in Figure 13, for the numerical simulation of uniaxial compression experiment. 

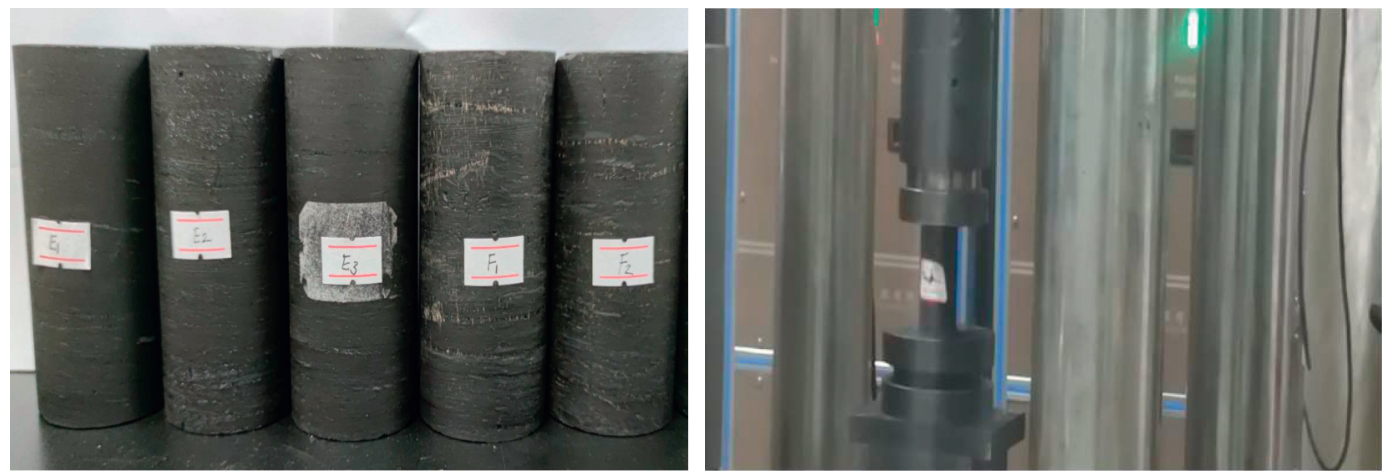

FIGURE 10: WAW31000 microcomputer-controlled electrohydraulic servo testing machine.

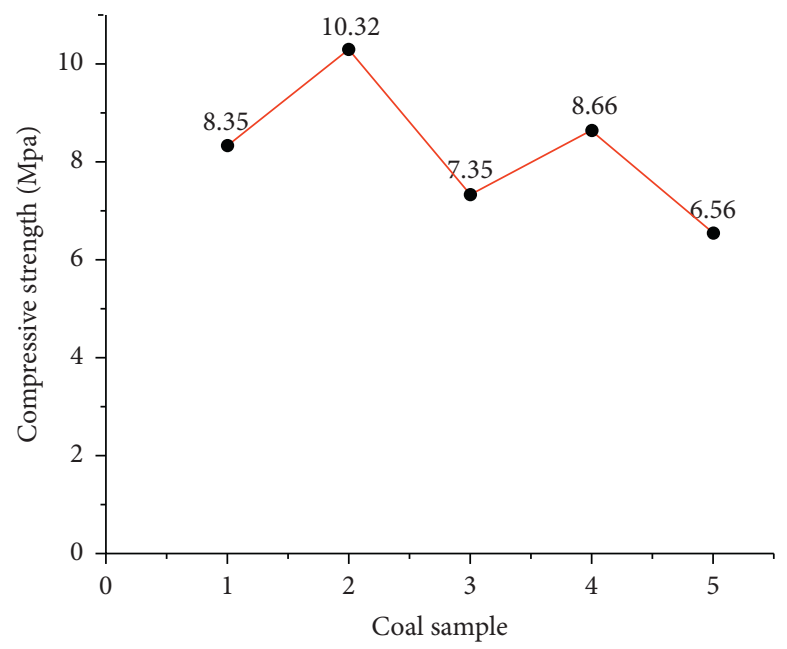

FIGURE 11: Uniaxial compressive strength of different coal samples.

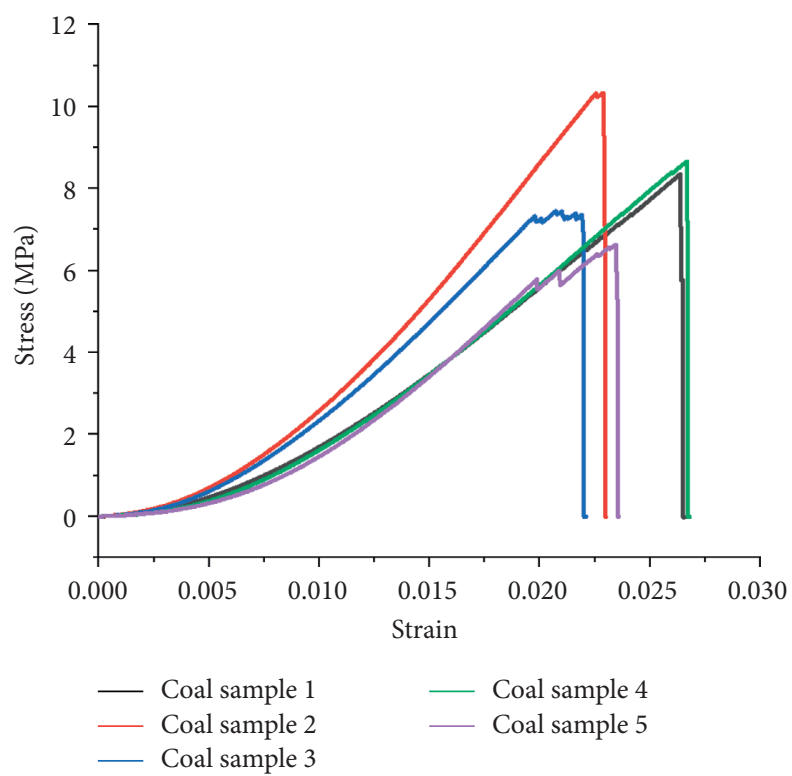

FIGURE 12: Uniaxial compressive strength of different coal samples. 


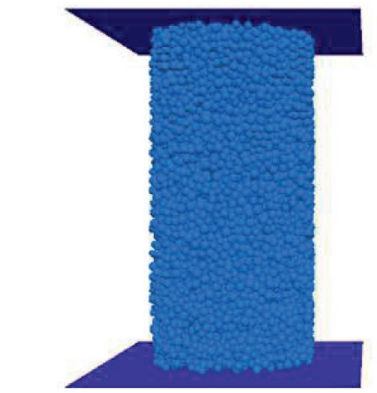

Three-dimensional reconstruction of coal sample

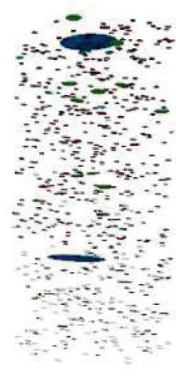

Primary joints

FIGURE 13: Numerical simulation test of uniaxial compression.

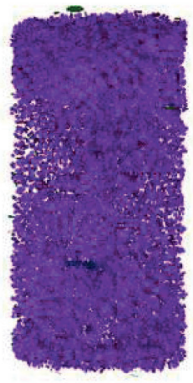

All joints
Post-cracking coal

sample

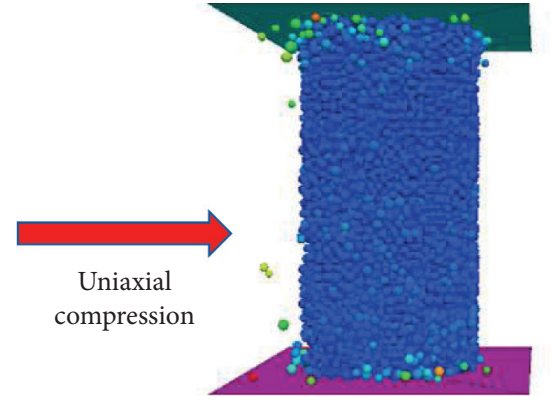

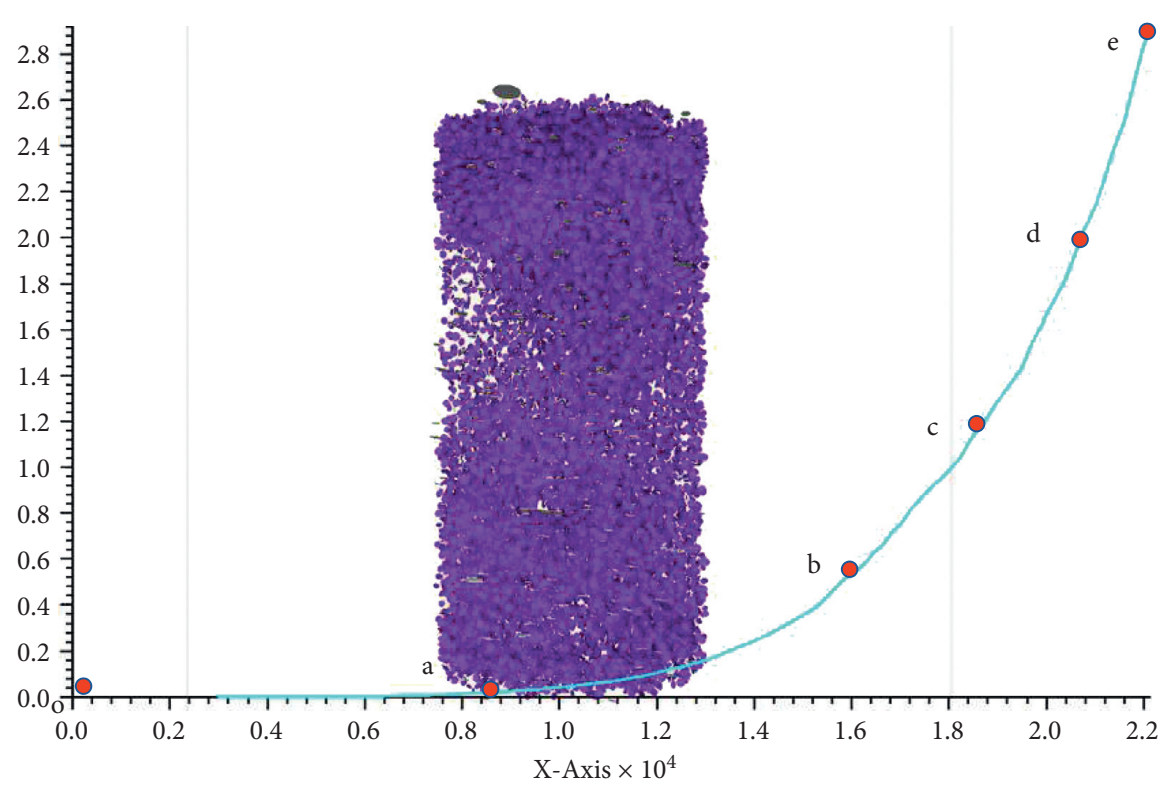

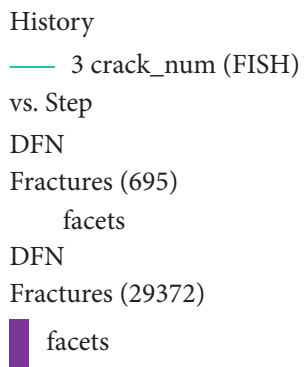

FIgURE 14: Statistical curve of the number of nodules in coal sample 4.

Figure 14 shows the statistical curve of the number of internal joints during uniaxial compression damage of coal sample 4, which is further analyzed in conjunction with the stress-strain curve of coal sample 4 (Figure 15(a)).

Stage I: the Oa section in Figures 14 and 15(a) belongs to the microjoint compacting stage. Combined with Figure 15(b), it can be seen that the microjoints in the coal sample are gradually compacted under pressure, and no secondary joints are produced in the first half of the $\mathrm{Oa}$ section in Figure 14. A small amount of microjoints are produced at the end of the coal sample and around some large-size joints at the later stage.

Stage II: the ab section in Figures 14 and 15(a) belongs to the elastic deformation stage, where the primary joints in the coal sample are further closed and compacted, and the pores are compressed, at which time the production of secondary joints inside the rock body begins to show a nonlinear trend, the ab curve in Figure 14 is slightly concave upward, and the number of secondary joints increases significantly. The 


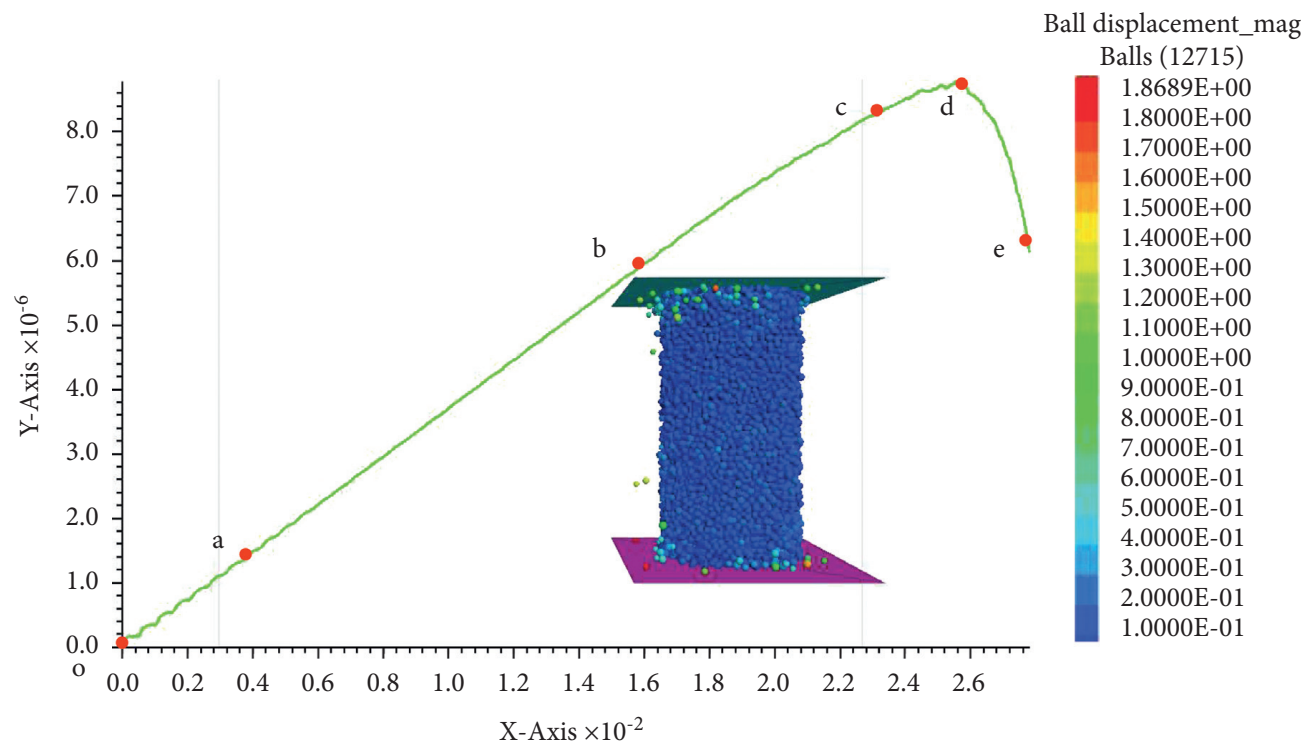

History

_ 1 axial_stress_wall (FISH)

vs. 2 axial_strain_wall (FISH)

(a)
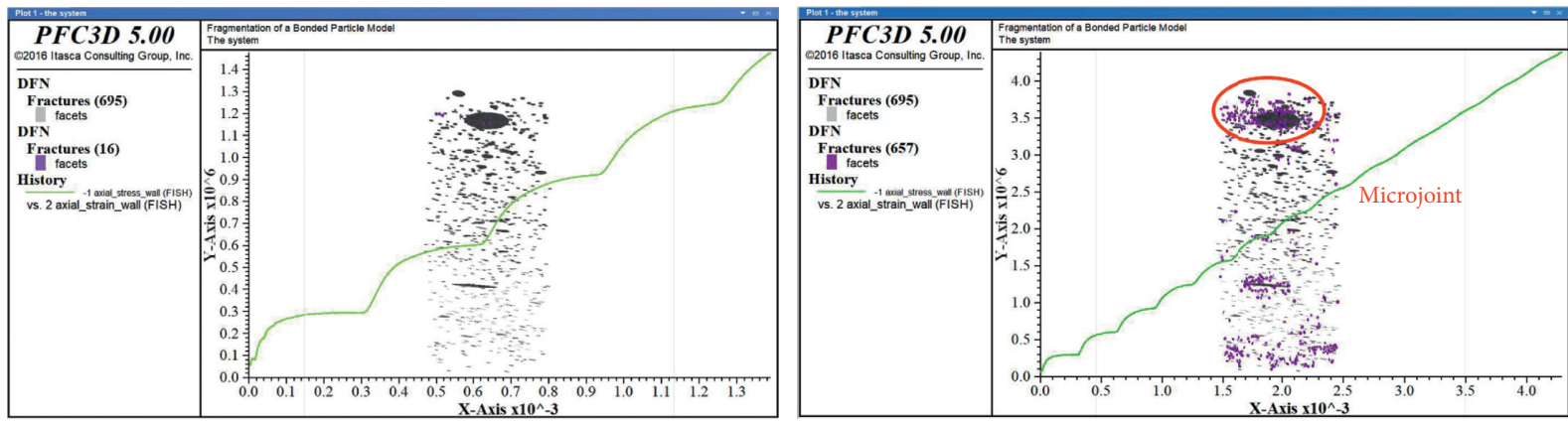

(b)
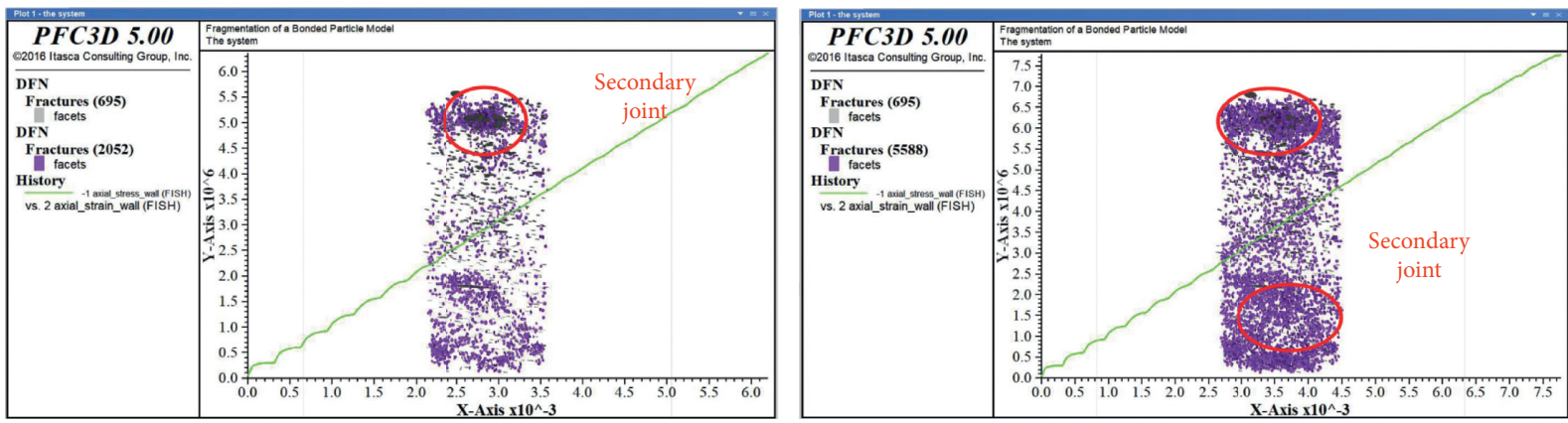

(c)

FIgURE 15: Continued. 

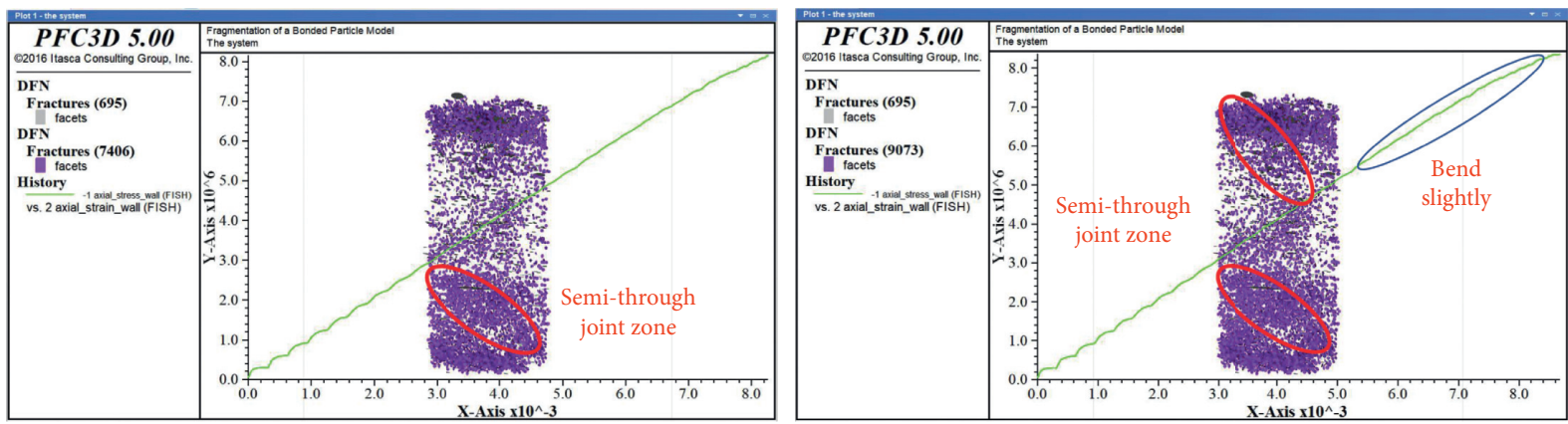

(d)
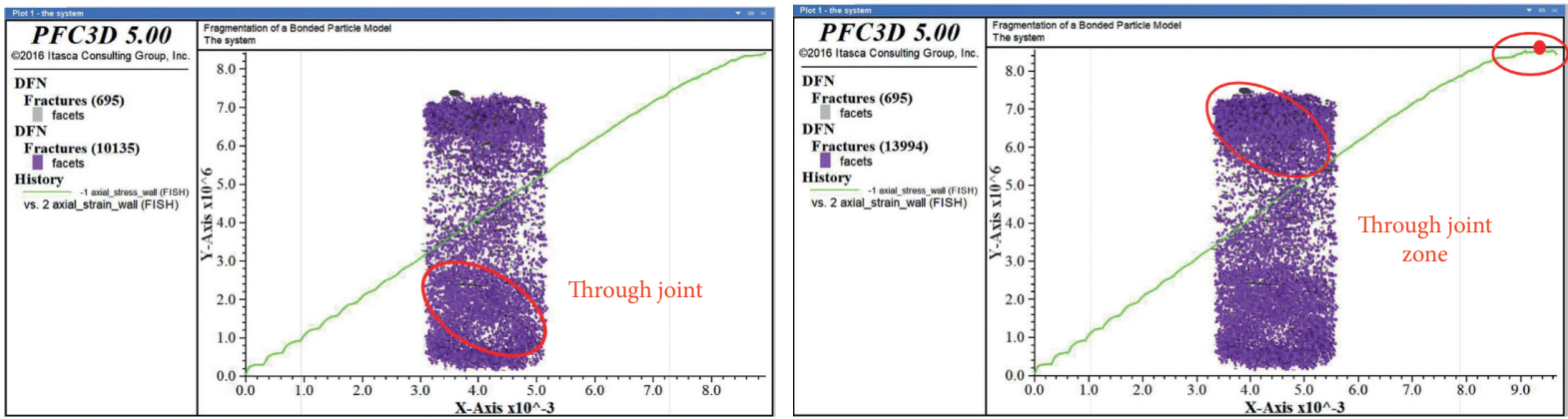

(e)
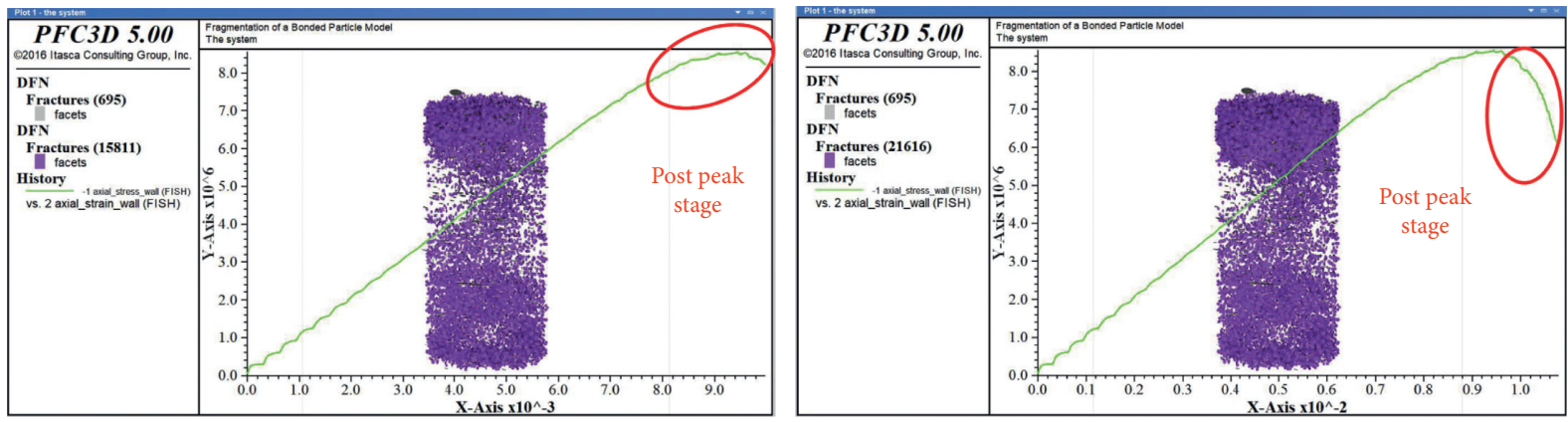

(f)

Figure 15: (a) Stress-strain curve for coal sample 4. (b) Joint compacting stage. (c) Elastic deformation stage. (d) Initial expansion phase. (e) Destruction phase. (f) Postpeak stage.

distribution range of joints in Figure 15(c) also gradually expands from the end, at the large-size primary joints, to the surrounding area. And the stress-strain curve of the coal sample is approximately straight line.

Stage III: the ab section in Figures 14 and 15(a) belongs to the initial expansion stage, and the deformation of the coal sample is mainly plastic deformation. The cumulative curve of the number of joints is steeper, and the rate of secondary joints generation is more accelerated, as in Figure 14. The deformation mechanism is that with the increase of secondary joints and the expanding range, partial semithrough fracture zones begin to form locally, as in Figure 15(d), and the stress-strain curve begins to turn from a straight line to a curve and is slightly concave downward, so this deformation stage can be regarded as the transition from elastic deformation to damage.
Stage IV: the section cd in Figures 14 and 15(a) belongs to the damage stage, in which the degree of through of the joints in the coal sample further deepens. Stress concentrations due to damage cause joints to expand and develop, and localized damage and deformation occur in some parts. Stress redistribution causes a large accumulation of joints in a short time, and the cumulative curve of the number of joints tends to $80^{\circ}$ (e.g., Figure 14). The deformation grows rapidly with the stress, and the stress reaches a maximum at point d, as shown in Figure 15(d).

Stage IV: the de section in Figures 14 and 15(a) belongs to the postpeak stage, where the bearing capacity is almost lost due to the macroscopic large deformation of the coal sample caused by the penetration of the joints, and the number of internal joints in the coal sample will still increase substantially at this time even if the external force remains unchanged. 
In summary, the mechanism of coal deformation and damage originates from the generation and accumulation effect of internal joints in the coal body, and the existence of joints has a significant influence on the secondary joint generation and the rupture process of the coal body under the action of load. The microjoint generation and development are mainly concentrated in the larger size and relatively concentrated area in the primary joints. With the increase of external load, the stress concentration effect caused by the fracture is significant, and the microjoint gradually accumulates to form a joint zone, which makes some weak parts destroy first and redistribute the stress, causing new joints to arise further. Due to the expansion of the joint distribution area, the rate of joint generation gradually increases, and the accumulated amount of joint shows an exponential change trend, which in turn leads to the macroscopic displacement and deformation of the coal body, making the volume expansion of the coal body accelerate, and the deformation grows rapidly with the stress, making the stress-strain of the coal body produce various stage-type changes. The cumulative curve of joint quantity during the rupture process shows a general change law of "basic constant-slow growth-exponential surge," which can well quantify and characterize the overall phase change process of the coal body and correspond to the characteristics of each phase of stress-strain evolution. Meanwhile, combined with the experimental results of five coal samples in the physical experiment, it can be strongly proved that the existence of joints is the main factor leading to the different physical properties of coal and deformation and damage. And the bearing capacity of coal body gradually decreases with the development and expansion of internal primary and secondary joints. The beginning of deformation stage of coal body originates from the closure and compression of internal joints. The overlap and expansion of internal joints make coal body damage and lose bearing capacity. Therefore, in order to study the influence of the physical properties of coal, it is necessary to conduct an in-depth study of the internal joints of the coal body first. Various complex joints (fissures), laminae, and other weak structural surfaces are very likely to lead to stress concentration and expansion of weak structural surfaces in the tunnel surroundings, and eventually destabilization and damage.

\section{Conclusion}

(1) Based on CT scanning technology to obtain a large number of nonthrough joints within the coal rock body, the scanning results are processed by Avizo software and effectively quantified by mathematical statistical methods. The results showed that the characteristic differences between joints within different coal samples are very significant, mainly in several aspects such as joints angle, joints size, joints distribution mode, and joints density. The characteristic parameters of joints within the same coal sample show nonuniform distribution, with accumulation effect in the size, angle, and distribution of joints.
(2) By conducting uniaxial compression experiments on the scanned coal samples, the stress-strain curves and strength variation trends of different coal samples are obtained, and combined with the table of internal joint characteristic parameters of coal samples, it is concluded that the larger the effective joint area and the larger the joint size inside the coal samples, the smaller the compressive strength of the coal samples; meanwhile, the increase of the joint size and area increased the ductility and multipeak phenomenon of the coal samples to some extent.

(3) The coal samples are reconstructed in three dimensions according to the scanning results, and then, uniaxial compression experiments are conducted to monitor and count the expansion process of internal joint development in the coal samples. In the macroscopic deformation process of the coal samples, the primary joints significantly influenced the secondary joint expansion, and the deformation mechanism of the coal samples is the increase and through of internal joints; meanwhile, the changes of each phase of the statistical curve of the number of joints and the phases of the stress-strain curve of the coal samples are adapted.

\section{Data Availability}

The data used to support the findings of this study are available from the corresponding author upon request.

\section{Conflicts of Interest}

The authors declare that they have no conflicts of interest.

\section{Acknowledgments}

This study was financially supported by the National Natural Science Foundation of China (52074166 and 5177419), the China Postdoctoral Science Foundation (2020T130385), National Natural Science Foundation of Shandong Province (ZR2021YQ38), and the Climbing Project of Taishan Scholar in Shandong Province (TSPD20210313).

\section{References}

[1] Q. Liu, L. Sun, and X. Tang, "Investigate the influence of the in-situ stress conditions on the grout penetration process in fractured rocks using the combined finite-discrete element method," Engineering Analysis with Boundary Elements, vol. 106, pp. 86-101, 2019.

[2] S. Fereshtenejad and J. J. Song, "Applicability of powder-based 3D printing technology in shear behavior analysis of rock mass containing non-persistent joints," Journal of Structural Geology, vol. 143, no. 10, pp. 204-251, 2021.

[3] V. Bonilla-Sierra, L. Scholtès, F. V. Donzé, and M. K. Elmouttie, "Rock slope stability analysis using photogrammetric data and DFN-DEM modelling," Acta Geotechnica, vol. 10, no. 4, pp. 497-511, 2015.

[4] G.. Liwei, J. P. Latham, and J. Xiang, "Numerical simulation of breakages of concrete armour units using a three-dimensional fracture model in the context of the combined finite-discrete 
element method," Computers \& Structures, vol. 146, pp. 117-142, 2015.

[5] Y.-S. Liu, H.-L. Fu, Y.-M. Wu, Y.-W. He, and H. Dong, "Study on brazilian splitting test for slate based on single weak plane theory," Journal of China Coal Society, vol. 38, pp. 1775-1780, 2013.

[6] X. Tan, H. Konietzky, T. Frühwirt, and D. Q. Dan, "Brazilian tests on transversely isotropic rocks: laboratory testing and numerical simulations," Rock Mechanics and Rock Engineering, vol. 48, no. 4, pp. 1341-1351, 2015.

[7] K. Y. Kim, L. Zhuang, H. Yang, H. Kim, and K.-B. Min, "Strength anisotropy of berea sandstone: results of X-ray computed tomography, compression tests, and discrete modeling," Rock Mechanics and Rock Engineering, vol. 49, no. 4, pp. 1201-1210, 2016.

[8] Z. Cui and Q. Sheng, "Numerical modelling of structural effect of equivalent mechanical parameters of fractured rock mass," Rock And Soil Mechanics, vol. 39, no. 10, pp. 38303840, 2018.

[9] B. Sun, G. Zhao, S. Zeng, J. Tan, and X. S. Deng, "Research on the influence of joint inclination angle on the mechanical properties of rock mass," Science And Technology, vol. 30, pp. 88-92, 2016.

[10] S. Q. Yang, M. Chen, and Y. Tao, "Experimental study on anchorage mechanical behavior and surface cracking characteristics of a non-persistent jointed rock mass," Rock Mechanics and Rock Engineering, vol. 54, no. 7, pp. 1-29, 2021.

[11] W. Peitao, L. Yu, Z. Liang, H. Zhengjun, and C. Meifeng, "Preliminary experimental study on uniaxial compressive properties of 3d printed fractured rock models," Chinese Journal of Rock Mechanics and Engineering, vol. 37, no. 2, pp. 364-373, 2018.

[12] X.-X. Yang, H.-W. Jing, C.-A. Tang, and S.-Q. Yang, "Effect of parallel joint interaction on mechanical behavior of jointed rock mass models," International Journal of Rock Mechanics and Mining Sciences, vol. 92, pp. 40-53, 2017.

[13] R. Liu, B. Li, Y. Jiang, and L. Yu, "A numerical approach for assessing effects of shear on equivalent permeability and nonlinear flow characteristics of 2-D fracture networks," Advances in Water Resources, vol. 111, pp. 289-300, 2018.

[14] V. Sarfarazi, H. Haeri, A. B. Shemirani, and Z. Zhu, "Shear behavior of non-persistent joint under high normal load," Strength of Materials, vol. 49, no. 2, pp. 320-334, 2017.

[15] H. Su, H. Jing, M. Du, and C. Wang, "Experimental investigation on tensile strength and its loading rate effect of sandstone after high temperature treatment," Arabian Journal of Geosciences, vol. 9, no. 13, pp. 1-11, 2016.

[16] L. Z. Wu, B. Li, R. Q. Huang, and P. Sun, "Experimental study and modeling of shear rheology in sandstone with nonpersistent joints," Engineering Geology, vol. 222, pp. 201-211, 2017.

[17] Z. Song, T. Frühwirt, and H. Konietzky, "Inhomogeneous mechanical behaviour of concrete subjected to monotonic and cyclic loading," International Journal of Fatigue, vol. 132, pp. 105-383, 2020.

[18] Z. Song, Y. Wang, H. Konietzky, and X. Cai, "Mechanical behavior of marble exposed to freeze-thaw-fatigue loading," International Journal of Rock Mechanics and Mining Sciences, vol. 138, pp. 104-648, 2021.

[19] G.-1. Zhou, T. Xu*, H. Konietzky et al., "An improved grainbased numerical manifold method to simulate deformation, damage and fracturing of rocks at the grain size level," Engineering Analysis with Boundary Elements, vol. 134, pp. 107-116, 2022.
[20] M. Asadizadeh, M. Moosavi, M. F. Hossaini, and H. Masoumi, "Shear strength and cracking process of non-persistent jointed rocks: an extensive experimental investigation," Rock Mechanics and Rock Engineering, vol. 51, no. 2, pp. 415-428, 2018.

[21] H. Song, Y. Zhao, Y. Jiang, and X. Zhang, "Influence of heterogeneity on the failure characteristics of coal under uniaxial compression condition," Journal of China Coal Society, vol. 42, pp. 3125-3132, 2017.

[22] Y.. Zhao, Study on Nonlinear Deterioration Effect of Joint Spatial Characteristic on Rock Mass Mechanical Properties, Shandong University of Science and Technology, Qingdao, China, 2021.

[23] F. C. Dai, C. F. Lee, J. H. Deng, and L. G. Tham, "The 1786 earthquake-triggered landslide dam and subsequent dambreak flood on the Dadu River, southwestern China," Geomorphology, vol. 65, no. 3-4, pp. 205-221, 2005.

[24] H. Drake, C. Heim, K. J. Hogmalm, and B. T. Hansen, "Fracture zone-scale variation of trace elements and stable isotopes in calcite in a crystalline rock setting," Applied Geochemistry, vol. 40, pp. 11-24, 2014.

[25] K. Esmaieli, J. Hadjigeorgiou, and M. Grenon, "Estimating geometrical and mechanical REV based on synthetic rock mass models at Brunswick Mine," International Journal of Rock Mechanics and Mining Sciences, vol. 47, no. 6, pp. 915-926, 2010.

[26] P. A. Cundall and O. D. L. Strack, "A discrete numerical model for granular assemblies," Géotechnique, vol. 29, no. 1, pp. $47-65,1979$. 